\title{
Body fluids from the rat exposed to chlorpyrifos induce cytotoxicity against the corresponding tissue-derived cells in vitro
}

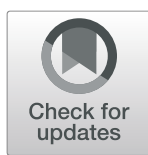

Yu-Jie Liang ${ }^{1,2}$, Ding-Xin Long ${ }^{2,3}$, Ming-Yuan $\mathrm{Xu}^{2}$, Hui-Ping Wang ${ }^{2}$, Ying-Jian Sun ${ }^{1 *}$ and Yi-Jun $\mathrm{Wu}^{2^{*}}$

\begin{abstract}
Background: This study aims to establish an in vitro monitoring approach to evaluate the pesticide exposures. We studied the in vitro cytotoxicity of three different body fluids of rats to the respective corresponding tissue-derived cells.

Methods: Wistar rats were orally administrated daily with three different doses of chlorpyrifos $(1.30,3.26$, and $8.15 \mathrm{mg} / \mathrm{kg}$ body weight/day, which is equal to the doses of $1 / 125,1 / 50$, and $1 / 20 L_{50}$, respectively) for consecutive 90 days. Blood samples as well as 24-hour urine and fecal samples were collected and processed. Then, urine, serum, and feces samples were used to treat the correspondent cell lines, i.e., T24 bladder cancer cells, Jurkat lymphocytes, and HT-29 colon cancer cells respectively, which derived from the correspondent tissues that could interact with the respective corresponding body fluids in organism. Cell viability was determined by using MTT or trypan blue staining.
\end{abstract}

Results: The results showed that urine, serum, and feces extract of the rats exposed to chlorpyrifos displayed concentration- and time-dependent cytotoxicity to the cell lines. Furthermore, we found that the cytotoxicity of body fluids from the exposed animals was mainly due to the presence of 3, 4, 5-trichloropyrindinol, the major toxic metabolite of chlorpyrifos.

Conclusions: These findings indicated that urine, serum, and feces extraction, especially urine, combining with the corresponding tissue-derived cell lines as the in vitro cell models could be used to evaluate the animal exposure to pesticides even at the low dose with no apparent toxicological signs in the animals. Thus, this in vitro approach could be served as complementary methodology to the existing toolbox of biological monitoring of long-term and low-dose exposure to environmental pesticide residues in practice.

Keywords: Pesticide, Exposure, Assessment, Body fluid, Cytotoxicity, Tissue-derived cell

\section{Introduction}

Due to the widespread use of pesticides worldwide, people are subject to environmental exposure to pesticide residues at some levels almost inevitably [1, 2].

\footnotetext{
*Correspondence: yjsun51@bua.edu.cn; wuyj@ioz.ac.cn

'Department of Veterinary Medicine and Animal Science, Beijing University of Agriculture, 102206 Beijing, PR China

'Laboratory of Molecular Toxicology, Institute of Zoology, Chinese Academy of Sciences, 100101 Beijing, PR China

Full list of author information is available at the end of the article
}

Thus, assessing the environmental exposure to humans is of great importance to the risk assessment [3]. The biological monitoring of exposure is a powerful tool for assessing environmental exposures to toxicants, which either determines the internal dose of a chemical by measuring the concentration of a chemical and its metabolites in given biologic matrices or measures the early biological effects of pesticides such as inhibition of acetylcholinesterase [4-6]. Urine and blood are two

C C The Author(s). 2021 Open Access This article is licensed under a Creative Commons Attribution 4.0 International License, which permits use, sharing, adaptation, distribution and reproduction in any medium or format, as long as you give appropriate credit to the original author(s) and the source, provide a link to the Creative Commons licence, and indicate if changes were made. The images or other third party material in this article are included in the article's Creative Commons licence, unless indicated otherwise in a credit line to the material. If material is not included in the article's Creative Commons licence and your intended use is not permitted by statutory regulation or exceeds the permitted use, you will need to obtain permission directly from the copyright holder. To view a copy of this licence, visit http://creativecommons.org/licenses/by/4.0/ The Creative Commons Public Domain Dedication waiver (http://creativecommons.org/publicdomain/zero/1.0/) applies to the data made available in this article, unless otherwise stated in a credit line to the data. 
major matrices that are used to assess exposure to chemicals $[7,8]$. However, the measurement of organic chemicals requires expensive instrumentations and highly trained analysts, which makes the measurement very costly, ranging from $\$ 100$ to $\$ 1500$ per sample depending on the sensitivity of the measurement [4]. And the dose-effect relationships for the measurement of the biological effectors such as the inhibition of acetylcholinesterase by pesticides are not fully established [5]. Thus, alternative approaches are needed for assessing the environmental exposure.

Various disease states could lead to drastic change in body fluids such as urine and serum [9]. Thus body fluids have been used in the diagnosis of various diseases; for example, a study showed that urine samples from patients with interstitial cystitis, a chronic bladder disease, could cause cytotoxicity to a bladder epithelial cell line in vitro $[10,11]$. Thus, the measurement of the antiproliferative activity of urine in the bladder-derived cell lines may be a useful noninvasive method for the diagnosis of bladder diseases [12]. Another example is that serum from patients with multiple sclerosis could cause demyelination in the cultured rat nerve tissues and induce cytotoxicity to the cultured rat oligodendrocytes [13].

However, the use of this indirect approach in exposure assessment to toxic chemicals has not been thoroughly explored. In this study, we used rats exposed chronically to low dose chlorpyrifos, a commonly used organophosphorus pesticide (OP), as the model for human and other mammalians exposure to environmental OPs. We sought to establish the indirect biological monitoring approach for environmental exposure assessment by measuring the cytotoxicity of different biological matrices from the chlorpyrifos-exposed rats in the following in vitro cell models. Bladder cells T24 were treated with correspondent urine samples. Colon cancer cells HT-29 were treated with correspondent feces extracts. Jurkat lymphocyte cells were treated with correspondent serum samples. MTT staining and trypan blue staining were used to measure cell viability. The cell model with the highest sensitivity and specificity may be used as to assess the environmental exposure and to study the mechanisms of toxicity of pesticides as well as other environmental pollutants.

\section{Materials and methods Materials}

Chlorpyrifos (purity $>95 \%$ ) was obtained from Shuangma Chemical Co. Ltd. (Jiangsu, China). RPMI1640, dimethyl sulfoxide (DMSO), and 3-(4,5-dimethylthiazol-2-yl)-2,5-diphenyltetrazolium bromide (MTT) were obtained from Sigma Aldrich Co. (St Louis, MO, USA). Dulbecco's modified Eagle's medium (DMEM) was obtained from Life Technologies (Carlsbad, CA, USA). Heat-inactivated fetal bovine serum (FBS) was obtained from Chuanye Biotechnology, Ltd (Tianjin, China). Bladder cancer cell line T24, colon cancer cell line HT-29 and lymphocyte cell line Jurkat were purchased from Cell Center of Chinese Academy of Medical Sciences (Beijing, China).

\section{Animals and treatment}

Forty 6-8-week old male Wistar rats with body weight of 150-220 g were obtained from Laboratory Animal Technology Company (Beijing, China). The animals were maintained at dark/light cycle of $12 \mathrm{~h}, 22 \pm 2{ }^{\circ} \mathrm{C}$ and $55 \pm 10 \%$ humidity. The rats were kept individually with free access to feed and water. Based on data from previous studies that the acute oral half-lethal doses $\left(\mathrm{LD}_{50}\right)$ of chlorpyrifos were $163 \mathrm{mg} / \mathrm{kg}$ for male rat [14], we chose the doses of $1 / 125,1 / 50$, and $1 / 20 \mathrm{LD}_{50}$ of chlorpyrifos as low dose $(1.30 \mathrm{mg} / \mathrm{kg}$ body weight), medium dose (3.26 $\mathrm{mg} / \mathrm{kg}$ body weight), and high dose $(8.15 \mathrm{mg} / \mathrm{kg}$ ) for the pesticide treatment groups in this study. The low dose of chlorpyrifos ( $1.30 \mathrm{mg} / \mathrm{kg}$ body weight) is close to the level of possible occupational exposure [15]. After 7 days of acclimatization, the animals were divided into three chlorpyrifos treatment groups (low dose: $1.30 \mathrm{mg}$ / $\mathrm{kg}$, medium dose: $3.26 \mathrm{mg} / \mathrm{kg}$, and high dose: $8.15 \mathrm{mg} /$ $\mathrm{kg}$ ) and one vehicle control group with 10 rats in each group. The pesticide was dissolved in corn oil $(0.5 \mathrm{ml} / \mathrm{kg}$ body weight) before being orally administered daily. The control group received an equivalent volume of corn oil daily. All of the animals were treated for consecutive 90 days to mimic the chronic exposure to pesticides in humans. At the end of the experiment, the samples of urine, feces, and blood were collected once from each of the animals (Fig. 1).

All animal procedures were performed in accordance with current China legislation and approved by the Animal and Medical Ethics Committee, which is affiliated to the Institute of Zoology, Chinese Academy of Sciences.

\section{Preparation of body fluids samples}

Ten milliliters $(10 \mathrm{~mL})$ of the collected 24-hour urine samples were processed with protein precipitation; the supernatant was lyophilized and suspended in $1 \mathrm{~mL}$ of phosphate buffer solution (PBS). The solution was sterilized by filtration with $0.22-\mu \mathrm{m}$ filters, and then diluted ten times by complete cell culture medium to make a stock solution, which was further diluted to treat cells to determine the dose-response effect of urine extract on cell viability.

Feces collected from animals were suspended in $0.1 \mathrm{M}$ cold PBS $(1: 5, \mathrm{w} / \mathrm{v})$ and then incubated with PBS buffer overnight with stirring. The solution was centrifuged at 


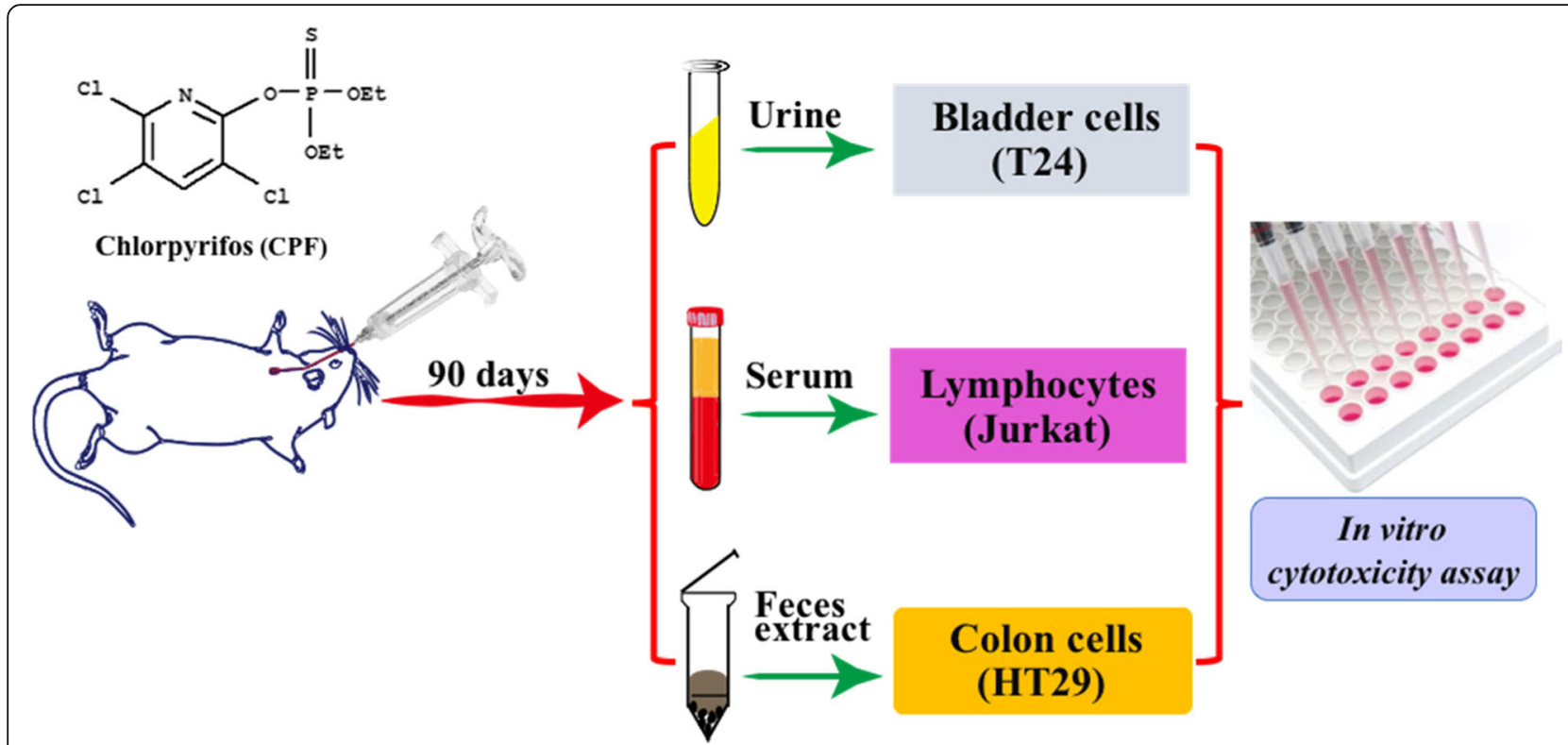

Fig. 1 Schematic illustration of the experiments with in vitro cytotoxicity of body fluids of rats toward the respective corresponding tissue-derived cells to reveal adverse effects of low-dose long-term exposure of chlorpyrifos

3, $000 \times \mathrm{g}$ for $30 \mathrm{~min}$ at $4{ }^{\circ} \mathrm{C}$ and then the supernatant was centrifuged at $15,000 \times \mathrm{g}$ for $30 \mathrm{~min}$ at $4{ }^{\circ} \mathrm{C}$. The supernatant was sterilized by filtration with $0.22 \mu \mathrm{m}$ filters and diluted ten times with cell culture medium, which was further diluted to treat cells to determine the dose-response effect of feces extract on cell viability.

Serum collected from the animals was heated at $56{ }^{\circ} \mathrm{C}$ for $30 \mathrm{~min}$ to inactivate complement proteins and potential mycoplasma, and then the serum was diluted ten times in complete cell culture medium containing $10 \%$ FBS to treat cells to determine the dose-response effect of the serum on cell viability.

\section{Cell culture and treatment}

The cells were cultured with DMEM (for T24 and HT29 cell lines) or RPMI-1640 (for Jurkat cell line) plus $10 \%$ FBS complemented with $100 \mathrm{U} / \mathrm{mL}$ penicillin and $100 \mu \mathrm{g} / \mathrm{mL}$ streptomycin. The cells were maintained at $37{ }^{\circ} \mathrm{C}$ in a humidified atmosphere containing $5 \% \mathrm{CO}_{2}$.

\section{MTT staining}

MTT staining was carried out according to the reference [16]. Briefly, T24 and HT-29 cells were seeded in 96well plates with $1 \times 10^{4}$ cells/well. After $24 \mathrm{~h}$, the urine stock solutions were added to T24 cells with different dilutions. Feces extracts were added to HT-29 cells with different dilutions. The corresponding urine and feces extracts from the vehicle-treated rats were also used to treat the cells, which served as vehicle controls. Culture medium was used as the negative control. After cells were treated for different time periods, $20 \mu \mathrm{l}$ of MTT $(5 \mathrm{mg} / \mathrm{ml})$ was added to each well. Four hours later, the cell culture medium was discarded and $150 \mu$ l of DMSO was added to each well. $\mathrm{OD}_{570}$ values were measured by using Bio-Rad Benchmark microplate reader. Each treatment was performed in triplicate and each experiment was repeated at least three times.

To eliminate possible non-specific interference from the samples, we determined the absorbance of the culture medium sparked with the prepared urine stock solution and feces extract samples under the cell-free condition (all other operations are the same as the MTT assay except for in the absence of cells). The result showed that no difference of the $\mathrm{OD}_{570}$ values was found between the culture medium group (blank) and the spiked medium group.

\section{Trypan blue staining}

Jurkat cells were seeded in 12 -well plate with $1 \times 10^{5}$ cells/ well. After $12 \mathrm{~h}$, the cells were treated with $300 \mu \mathrm{l}$ of the 10 -fold diluted serum from the rats treated with $1.30 \mathrm{mg} /$ $\mathrm{kg}, 3.26 \mathrm{mg} / \mathrm{kg}$, or $8.15 \mathrm{mg} / \mathrm{kg}$ chlorpyrifos, respectively. After cultured for different time periods, cells were stained by trypan blue and the live cell number in each well was counted. Serum samples from the corn oil-treated rats were used as the vehicle control and $10 \%$ FBS in regular cell culture medium was used as the negative control. Each treatment was performed in triplicate and each experiment was repeated at least three times. 
Determination of chlorpyrifos and TCP levels in the serum and urine

The assay of chlorpyrifos and its metabolite 3, 4, 5trichloropyrindinol (TCP) was carried out according to the method of the previous study [17]. Briefly, $200 \mu \mathrm{l}$ of the serum or urine were added to $600 \mu \mathrm{l}$ of acetic ether and vortexed for $1 \mathrm{~min}$. The solution was centrifuged at 1 , $000 \times \mathrm{g}$ for $20 \mathrm{~min}$ and then the supernatants were collected, dried under nitrogen and then dissolved in $150 \mu \mathrm{l}$ of methanol. The solution was centrifuged at $15,000 \times \mathrm{g}$ for $20 \mathrm{~min}$ and then the supernatants were transferred into the vials. The samples were analyzed by the Agilent 1100 series HPLC system (Agilent Co., USA).

\section{Statistics}

All data are presented as mean \pm Standard Error of the Mean (SEM). Statistical differences between treated and control groups were evaluated by GraphPad Prism 8.0 (SanDiego, CA, USA). The one-way Analysis of Variance (ANOVA) test followed by the post hoc Dunnett's test was performed to access significant differences among all the groups. The difference was considered significant if the p-value was less than 0.05 .

\section{Results}

\section{Symptoms and body weight changes of CPF-treated rats}

There were no deaths of the rats during the course of the whole study. Rats treated with chlorpyrifos for 90 consecutive days did not demonstrate overt signs of toxicity probably due to the very low dose of chlorpyrifos used in this study. The rats in all treatment groups progressively gained weight over the 90-day period; however, there were no significant differences between body weights of chlorpyrifos-treated rats and that of vehicle control rats (data not shown).

\section{The cytotoxicity of the urine prepared to T24 bladder cells}

Bladder cancer cell line T24 cells were treated with the urine prepared from the rats exposed to chlorpyrifos. The cell shape became round and the cytosol was condensed (Fig. 2). The changes were more prominent in groups treated with urine samples from the rats exposed to high dose of chlorpyrifos (8.15 mg/kg/day) (Fig. 2).

The cell viability of T24 cells decreased after treated with urine samples from the rats exposed to the medium dose of chlorpyrifos $(3.26 \mathrm{mg} / \mathrm{kg} /$ day $)$ (Fig. 3 A). The cytotoxicity increased in a concentration- and cell exposure time-dependent manner. Treatment for $72 \mathrm{~h}$ had a similar effect to the treatment for $48 \mathrm{~h}$. Thus the following experiments used 48-hour treatment. The cytotoxicity was higher in cells treated with urine samples from the rats exposed to higher dose of chlorpyrifos (Fig. 3B).

\section{The cytotoxicity of the feces extracts to HT-29 colon cells} The cell viability of colon cancer cell line HT-29 cells decreased after treated with feces extracts from the rats exposed to medium dose of chlorpyrifos $(3.26 \mathrm{mg} / \mathrm{kg} /$ day) for $48 \mathrm{~h}$ (Fig. $4 \mathrm{~A}$ ). The cytotoxicity escalated as the fecal treatment concentration and cell exposure time increased. The cytotoxicity was higher in cells treated with feces extract from the rats exposed to higher dose of chlorpyrifos (Fig. 4B). The cytotoxicity of the fecal control extract also increased
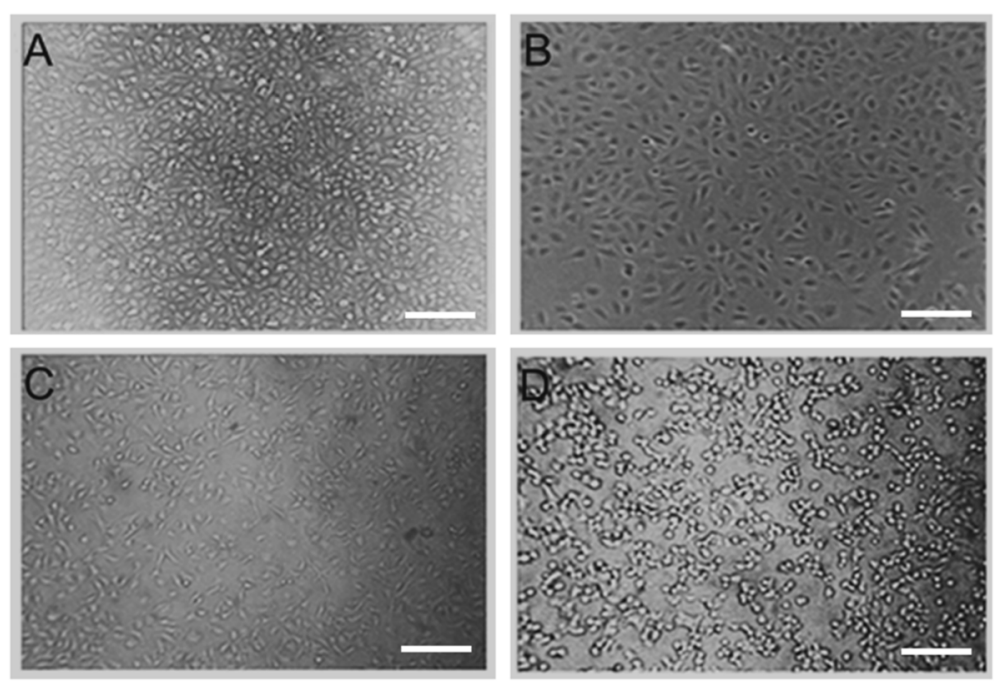

Fig. 2 Morphological changes of T24 cells treated with the urine prepared from rats exposed to chlorpyrifos (CPF) at doses of $0 \mathrm{mg} / \mathrm{kg} / \mathrm{day}$ (A), $1.30 \mathrm{mg} / \mathrm{kg} /$ day (B), $3.26 \mathrm{mg} / \mathrm{kg} /$ day (C), and $8.15 \mathrm{mg} / \mathrm{kg} /$ day (D). Scale bars $=200 \mu \mathrm{m}$ 


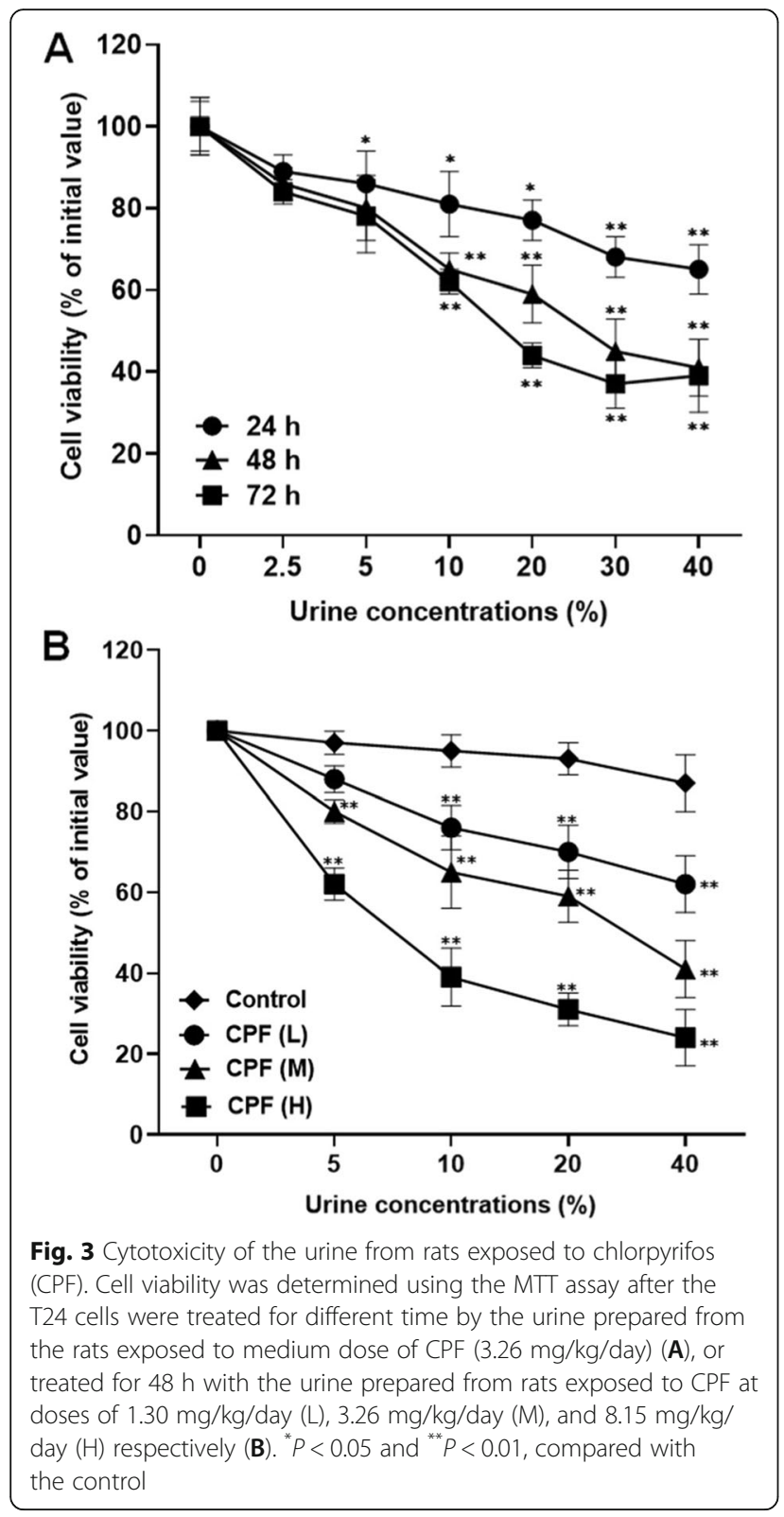

significantly but less so than the chlorpyrifos exposure treatment samples (Fig. 4B).

\section{The cytotoxicity of the serum prepared to lymphocyte} cells

The live cell number of Jurkat lymphocytes decreased after treated with the 10-fold diluted serum from the rats exposed to different doses of chlorpyrifos, as measured using the trypan blue assay (Fig. $5 \mathrm{~A}$ ). The cytotoxicity increased in a chlorpyrifos concentration- and cell exposure time-dependent manner. After Jurkat cells were treated with serum samples from the rats exposed to high dose of chlorpyrifos for $24 \mathrm{~h}$, the cell number

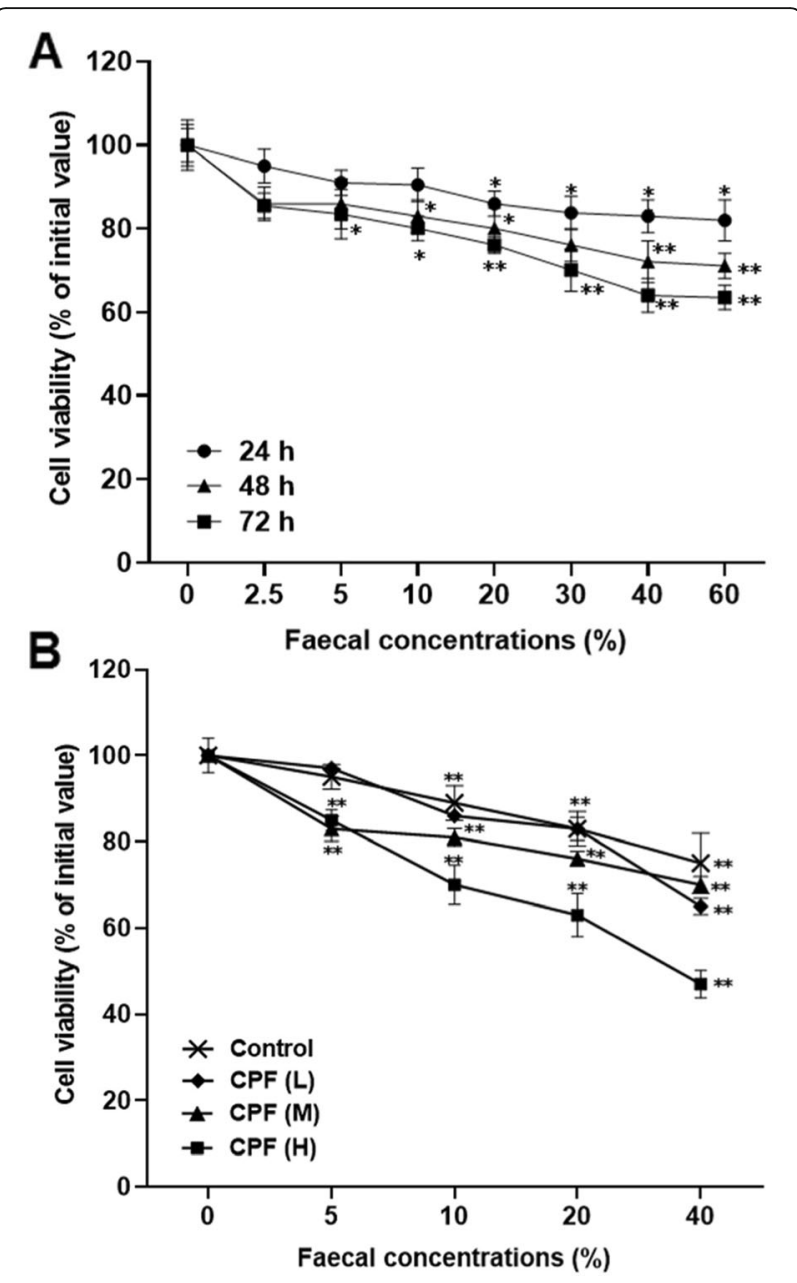

Fig. 4 Cytotoxicity of the feces extracts from rats exposed to chlorpyrifos (CPF). Cell viability was determined using the MTT assay after the HT-29 cells were treated by the feces extracts from the rats exposed to medium dose of CPF (3.26 mg/ $\mathrm{kg} /$ day) for different time (A) or treated for $48 \mathrm{~h}$ with the feces extracts from rats exposed to CPF at doses of $1.30 \mathrm{mg} / \mathrm{kg} /$ day (L), $3.26 \mathrm{mg} / \mathrm{kg} /$ day $(\mathrm{M})$, and $8.15 \mathrm{mg} / \mathrm{kg} /$ day $(\mathrm{H})$, respectively $(\mathbf{B}) .{ }^{*} P<0.05$ and ${ }^{* *} P<0.01$, compared with the control

significantly decreased $32.3 \%$ and $44.6 \%$ compared with that of the cells treated with serum samples from vehicle control rats or with $10 \%$ FBS in regular cell culture medium (negative control cells), respectively (Fig. 5B). After treated for $72 \mathrm{~h}$, the number of the cells significantly decreased $60.5 \%$ and $79.7 \%$ compared with that of the cells treated with serum samples from vehicle control rats or with $10 \%$ FBS in regular cell culture medium (negative control cells), respectively (Fig. 5B).

The levels of chlorpyrifos and its metabolite in the serum and urine

After 90-day chlorpyrifos exposure, the chlorpyrifos concentration in the serum detected was not obviously 


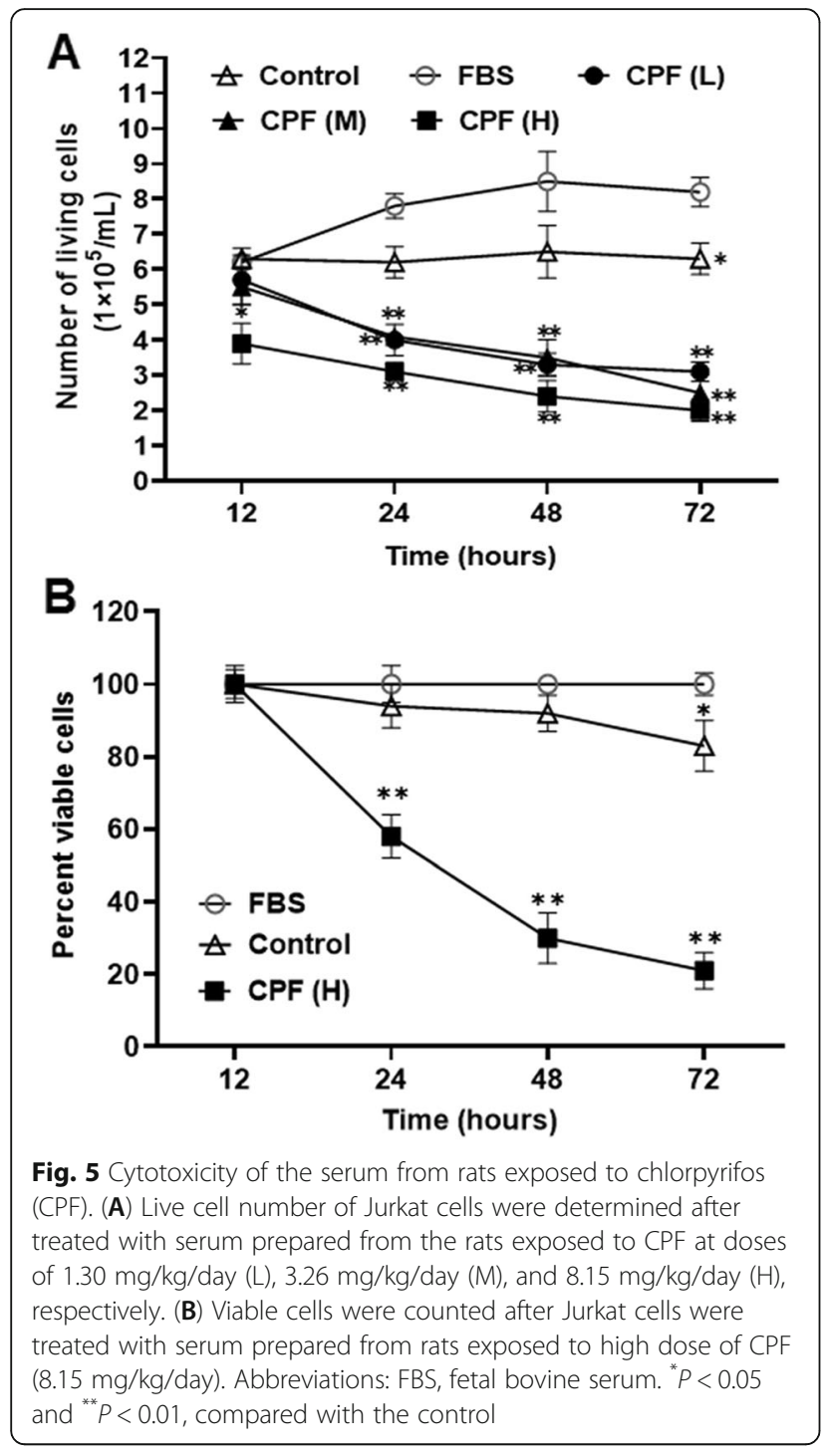

different among the three doses groups; however, the level of chlorpyrifos in the urine from the rats exposed to the high dose of chlorpyrifos $(8.15 \mathrm{mg} / \mathrm{kg} /$ day $)$ is higher than that in the other two doses groups. There is no obvious difference of the chlorpyrifos content between the serum and urine, while the levels of TCP, a chlorpyrifos metabolite, not only are much higher in urine than that in serum but also increased in both serum and urine as the administration dose increased (Table 1).

\section{Discussion}

The biological monitoring of organophosphorus pesticides exposure usually relies on the measurement of serum levels of the pesticide and its metabolite or acetylcholinesterase activity in the population [5]. The current study proposed a novel approach to monitor
Table 1 The levels of chlorpyrifos and its metabolite TCP in the serum and urine of the rats exposed to different doses of chlorpyrifos for 90 days

\begin{tabular}{|c|c|c|c|c|}
\hline \multirow[t]{2}{*}{ Groups } & \multicolumn{2}{|l|}{$\mathrm{CPF}(\mu \mathrm{g} / \mathrm{ml})$} & \multicolumn{2}{|l|}{$\mathrm{TCP}(\mu \mathrm{g} / \mathrm{ml})$} \\
\hline & Serum & Urine & Serum & Urine \\
\hline Control & ND & ND & ND & ND \\
\hline CPF-L & $0.007 \pm 0.001$ & $0.007 \pm 0.001$ & $0.025 \pm 0.007^{*}$ & $4.463 \pm 0.808^{*}$ \\
\hline CPF-M & $0.005 \pm 0.000$ & $0.008 \pm 0.002$ & $0.054 \pm 0.008^{*}$ & $39.135 \pm 8.521^{*}$ \\
\hline CPF-H & $0.009 \pm 0.002$ & $0.021 \pm 0.008^{* *}$ & $0.084 \pm 0.007^{*}$ & $58.853 \pm 6.948^{*}$ \\
\hline
\end{tabular}

Note: ${ }^{*} P<0.05$ and ${ }^{* *} P<0.01$, compared with the control. Abbreviations:

$N D$ not detected, CPF chlorpyrifos, TCP trichloropyrindinol, $L$ low

dose, $M$ medium dose, $H$ high dose

organophosphorus pesticide chlorpyrifos exposure in the population by measuring the cytotoxicity of body fluids to in vitro cultured cells (T24, HT-29, and Jurkat cells). The results showed that the cytotoxicity of the body fluids to the cultured cells reliably reflected the dose of chlorpyrifos administered to the tested animals.

After chemicals are absorbed by an organism into the circulation and distributed into organs, the chemicals are metabolized and excreted from the body. The residues of chlorpyrifos metabolite TCP are usually detected in the urine, blood, and other body fluids of human and other animals when exposed to chlorpyrifos [18-20]. And TCP has been used as a biomarker of chlorpyrifos exposure. However, TCP was found to be even more toxic than its parent compound chlorpyrifos [21-23]. Thus, the cytotoxicity of body fluids from the exposed animals was due to not only chlorpyrifos itself but also the presence of its metabolites, since the corresponding different levels of chlorpyrifos and much higher levels of the metabolite TCP were found in the urine and serum of the rats exposed to chlorpyrifos (Table 1). It suggests that TCP could be involved mainly in the cytotoxicity of chlorpyrifos exposure. Studies have clarified that TCP is the main factor in negative influence of chlorpyrifos [24]. Since bladder is the main organ for storing urine, the effect of TCP on the cells derived from bladder tissue is worthy of further study. Urine is best suited for non-invasive diagnosis and monitoring because it is easy to obtain and process. In addition, urine contains a variety of metabolic products [25]. Thus urine samples from vehicle-treated animals inhibited cell viability to some extent as well; however, the cytotoxicity of urine samples reflected the low-dose exposure of the pesticide.

We all know that traditional toxicological risk assessment focuses on the "direct" assay for the effect of chemical on cultured cells in vitro or laboratory animals in vivo. The traditional toxicology methods mainly rely on whole animal experiments to assess the impact of xenobiotics on human and ecological health. However, it is not easy to understand accurately the effect of a chemical on specific organs after being metabolized in the 
body especially at the existence of multiple metabolic products of the tested chemical in the body. Our results suggested that the cytotoxicity test analysis of body fluids from the animals exposed to pesticide could expand the application of the traditional toxicity tests in vitro and maximize the use of the in vivo animal experiment tests.

In this study, we used the cultured cell lines as cell models, which are corresponding to the organs of body, to do the toxicity test as a viable alternative. Overall, our results showed that urine, serum, and fecal extract can reflect the long-term exposure of pesticides even at environmental residue levels with no apparent toxicological signs. However, this cytotoxicity endpoint assay is not a reliable surrogate for quantitative exposure biomonitoring where a specific chemical is identified and quantified in a biological compartment. We expected that in the future studies, more advanced effective alternatives such as primary cells from the corresponding organs, 3D cell models, and tissue slices would be used for more accurately evaluating the changes of body environment to identify the toxicities of the exposed chemicals.

\section{Conclusions}

This study proposes that the cytotoxicity measurement of the cells, which are from three organ-derived cell lines, incubated with the corresponding body fluids could be used to monitor the exposure and toxicity of the residues of pesticides in the body. This simple assay in vitro approach could be served as a complementary methodology to identify the toxicities of the long-term and low-dose exposure of pesticides or other environmental pollutants.

\section{Acknowledgements}

We appreciate Dr. Pan Wang for her assistance in preparation of the manuscript draft.

\section{Authors' contributions}

Y.J.S., D.X.L. and Y.J.W. designed the experiments. Y.J.L., D.X.L., M.Y.X. and H.P.W. conducted the experiments. Y.J.L. and Y.J.W. wrote the main manuscript text. Y.J.L. and Y.J.S. prepared the figures. All authors reviewed the manuscript. The author(s) read and approved the final manuscript.

\section{Funding}

This work was supported in part by grants from the National High Technologies R\&D Program (2006AA06Z423) and CAS Innovation Program (No. KZCX2-EW-404).

\section{Availability of data and materials}

All data generated or analyzed during this study are included in this published article.

\section{Declarations}

\section{Ethics approval and consent to participate}

All animal procedures were performed in accordance with current China legislation and approved by the Animal and Medical Ethics Committee, which is affiliated to the Institute of Zoology, Chinese Academy of Sciences. All procedures were carried in accordance with the ARRIVE (Animal Research: Reporting In Vivo Experiments) guidelines.
Consent for publication

All authors agree with the submission.

\section{Competing interests}

There is no conflict of interest regarding the publication of this paper.

\section{Author details}

${ }^{1}$ Department of Veterinary Medicine and Animal Science, Beijing University of Agriculture, 102206 Beijing, PR China. 'Laboratory of Molecular Toxicology, Institute of Zoology, Chinese Academy of Sciences, 100101 Beijing, PR China.

${ }^{3}$ School of Public Health, University of South China, 421001 Hengyang, P. R. China.

Received: 27 March 2021 Accepted: 22 September 2021

Published online: 20 October 2021

\section{References}

1. Egeghy PP, Cohen Hubal EA, Tulve NS, Melnyk L, Morgan MK, Fortmann $\mathrm{RC}$, Sheldon LS. Review of pesticide urinary biomarker measurements from selected US EPA children's observational exposure studies. Int J Environ Res Public Health. 2011;8:1727-1754.

2. Mostafalou S, Abdollahi M. Pesticides: an update of human exposure and toxicity. Arch Toxicol. 2017;91:549-599.

3. Cimino AM, Boyles AL, Thayer KA, Perry MJ. Effects of neonicotinoid pesticide exposure on human health: A systematic review. Environ Health Perspect. 2017;125:155-162

4. Barr DB, Wang RY, Needham LL. Biologic monitoring of exposure to environmental chemicals throughout the life stages: requirements and issues for consideration for the National Children's Study. Environ Health Perspect. 2005:113:1083-1091.

5. Maroni M, Colosio C, Ferioli A, Fait A. Biological monitoring of pesticide exposure: a review. Toxicology. 2000;143:1-118.

6. Sexton K, Callahan MA, Bryan EF. Estimating exposure and dose to characterize health risks: the role of human tissue monitoring in exposure assessment. Environ Health Perspect. 1995:103 (suppl 3):13-29.

7. Barr JR, Driskell WJ, Hill Jr RH, Ashley DL, Needham LL, Head SL, Sampson EJ, Barr DB. Strategies for biological monitoring of exposure for contemporary-use pesticides. Toxicol Ind Health. 1999;15:169-180.

8. Needham LL, Sexton KEN. Assessing children's exposure to hazardous environmental chemicals: an overview of selected research challenges and complexities. J Expo Sci Environ Epidemiol. 2000;10 (6 Pt 2):611-619.

9. Dorne $\mathrm{J}$, Walton K, Renwick AG. Human variability in xenobiotic metabolism and pathway-related uncertainty factors for chemical risk assessment: a review. Food Chem Toxicol. 2005:43:203-216.

10. Beier-Holgersen R, Hermann GG, Mortensen SO, Steven K. The in vitro cytotoxicity of urine from patients with interstitial cystitis. J Urol. 1994;151: 206-207.

11. Keay S, Zhang CO, Trifillis AL, Hise MK, Hebel JR, Jacobs SC, Warren JW. Decreased ${ }^{3} \mathrm{H}$-thymidine incorporation by human bladder epithelial cells following exposure to urine from interstitial cystitis patients. J Urol. 1996; 156:2073-2078.

12. Keay S, Zhang CO, Hise MK, Hebel JR. Jacobs SC, Gordon D, Whitmore K, Bodison S, Gordon N, Warren JW. A diagnostic in vitro urine assay for interstitial cystitis. Urology. 1998:52:974-978.

13. Ruijs TC, Olivier A, Ante JP. Serum cytotoxicity to human and rat oligodendrocytes in culture. Brain Res. 1990;517:99-104.

14. Worthing CR, Walker SB. The Pesticide Manual: A World Compendium (8th ed). The British Crop Protection Council. Thornton Heath, UK. 1987.

15. Xu MY, Wang P, Sun YJ, Yang L, Wu YJ. Joint toxicity of chlorpyrifos and cadmium on the oxidative stress and mitochondrial damage in neuronal cells. Food Chem Toxicol. 2017;103:246-252.

16. Sargent JM, Taylor CG. Appraisal of the MTT assay as a rapid test of chemosensitivity in acute myeloid leukemia. Brit J Cancer. 1989;60:206-207.

17. Abu-Qare AW, Abou-Donia MB. Determination of diazinon, chlorpyrifos, and their metabolites in rat plasma and urine by high-performance liquid chromatography. J Chromatogr Sci. 2001;39:200-204.

18. Wilson NK, Chuang JC, Lyu C, Menton R, Morgon MK. Aggregate exposure of nine preschool children to persistent organic pollutants at day care and at home. J Expo Anal Environ Epidemiol. 2003;13:187-202.

19. Timchalk C, Campbell JA, Liu G, Lin Y, Kousba AA. Development of a noninvasive biomonitoring approach to determine exposure to the 
organophosphorus insecticide chlorpyrifos in rat saliva. Toxicol Appl Pharmacol. 2007;219(2-3):217-225.

20. Phung DT, Connell D, Miller G, Chu C. Probabilistic assessment of chlorpyrifos exposure to rice farmers in Viet Nam. J Expo Sci Environ Epidemiol. 2012;22(4):417-423.

21. Cáceres T, He W, Naidu R, Megharaj M. Toxicity of chlorpyrifos and TCP alone and in combination to Daphnia carinata: the influence of microbial degradation in natural water. Water Res. 2007:41:4497-4503.

22. Hanley-Jr TR, Carney EW, Johnson EM. Developmental toxicity studies in rats and rabbits with 3, 5, 6-trichloro-2-pyridinol, the major metabolite of chlorpyrifos. Toxicol Sci. 2000;53:100-108.

23. Suvarchala G, Philip GH. Toxicity of 3, 5, 6-trichloro-2-pyridinol tested at multiple stages of zebrafish (Danio rerio) development. Environ Sci Pollut Res. 2016;23:15515-15523.

24. Li J, Fang B, Ren F, Xing H, Zhao G, Yin X, Pang G, Li Y. TCP structure intensified the chlorpyrifos-induced decrease in testosterone synthesis via LH-LHR-PKA-CREB-Star pathway. Sci Total Environ. 2020;726:138496.

25. Parsons CL, Bautista SL, Stein PC, Zupkas P. Cyto-injury factors in urine: a possible mechanism for the development of interstitial cystitis. J Urol. 2000; 164:1381-1384

\section{Publisher's Note}

Springer Nature remains neutral with regard to jurisdictional claims in published maps and institutional affiliations.

Ready to submit your research? Choose BMC and benefit from:

- fast, convenient online submission

- thorough peer review by experienced researchers in your field

- rapid publication on acceptance

- support for research data, including large and complex data types

- gold Open Access which fosters wider collaboration and increased citations

- maximum visibility for your research: over $100 \mathrm{M}$ website views per year

At BMC, research is always in progress.

Learn more biomedcentral.com/submissions 